\title{
Article \\ Detecting the Mechanism behind the Transition from Fixed Two-Dimensional Patterned Sika Deer (Cervus nippon) Dermal Papilla Cells to Three-Dimensional Pattern
}

\author{
Guanning Wei ${ }^{1,2}$, Hongmei Sun ${ }^{2, *}$, Haijun Wei ${ }^{2}$, Tao Qin ${ }^{3}$, Yifeng Yang ${ }^{2}$, Xiaohong $\mathrm{Xu}^{4}$ and Shoujing Zhao ${ }^{1, *}$ \\ 1 School of Life Sciences, Jilin University, Changchun 130012, China; weign16@mails.jlu.edu.cn \\ 2 Institute of Special Wild Economic Animals and Plants, Chinese Academy of Agricultural Sciences, \\ 4899 Juye Street, Changchun 130112, China; weihaijun@caas.cn (H.W.); yangyifeng@caas.cn (Y.Y.) \\ 3 School of Ecology and Environment, Northwestern Polytechnical University, Xi'an 710072, China; \\ wqqt@mail.nwpu.edu.cn \\ 4 Laboratory of Infectious Diseases, College of Veterinary Medicine, Jilin University, Changchun 130062, China; \\ xuxiaohong@jlu.edu.cn \\ * Correspondence: sunhongmei@caas.cn (H.S.); swgc@jlu.edu.cn (S.Z.)
}

Citation: Wei, G.; Sun, H.; Wei, H.; Qin, T.; Yang, Y.; Xu, X.; Zhao, S.

Detecting the Mechanism behind the Transition from Fixed

Two-Dimensional Patterned Sika Deer (Cervus nippon) Dermal Papilla Cells to Three-Dimensional Pattern. Int. J. Mol. Sci. 2021, 22, 4715. https://doi.org/10.3390/ ijms22094715

Received: 13 February 2021

Accepted: 20 April 2021

Published: 29 April 2021

Publisher's Note: MDPI stays neutral with regard to jurisdictional claims in published maps and institutional affiliations.

Copyright: (c) 2021 by the authors. Licensee MDPI, Basel, Switzerland. This article is an open access article distributed under the terms and conditions of the Creative Commons Attribution (CC BY) license (https:// creativecommons.org/licenses/by/ $4.0 /)$.

\begin{abstract}
The hair follicle dermal papilla is critical for hair generation and de novo regeneration. When cultured in vitro, dermal papilla cells from different species demonstrate two distinguishable growth patterns under the conventional culture condition: a self-aggregative three dimensional spheroidal (3D) cell pattern and a two dimensional (2D) monolayer cell pattern, correlating with different hair inducing properties. Whether the loss of self-aggregative behavior relates to speciesspecific differences or the improper culture condition remains unclear. Can the fixed 2D patterned dermal papilla cells recover the self-aggregative behavior and 3D pattern also remains undetected. Here, we successfully constructed the two growth patterns using sika deer (Cervus nippon) dermal papilla cells and proved it was the culture condition that determined the dermal papilla growth pattern. The two growth patterns could transit mutually as the culture condition was exchanged. The fixed 2D patterned sika deer dermal papilla cells could recover the self-aggregative behavior and transit back to 3D pattern, accompanied by the restoration of hair inducing capability when the culture condition was changed. In addition, the global gene expressions during the transition from 2D pattern to 3D pattern were compared to detect the potential regulating genes and pathways involved in the recovery of $3 \mathrm{D}$ pattern and hair inducing capability.
\end{abstract}

Keywords: sika deer; dermal papilla cell; 3D pattern; 2D pattern; hair inducing capability

\section{Introduction}

Dermal papilla (DP) is a spherical or pear-shaped specialized mesenchymal condensation that is embedded in the hair bulb at the base of the follicle, enclosed by epithelial matrix keratinocytes [1]. The transplanting experiments of postnatal DP from various origins, such as feathers, pelage, and hairs, proved DP plays a key role in inducing hair follicle neogenesis in both follicular and non-hair-bearing skin [2-5]. In the process of hair generation and regeneration, DP instructs the keratinocytes to constitute the hair shaft and inner root sheath during the anagen phase [6-8]. The structure of DP is relatively simple, consisting of a predominant single cell type: DP cells [9]. In vitro, DP cells from different species demonstrate two distinctive patterns under conventional serum containing culture conditions: two dimensional (2D) monolayer polygonal pattern and three dimensional (3D) spheroidal pattern. In reported assays, DP cells from ovine wool follicles [10] and rodent vibrissa follicles $[11,12]$ can spontaneously aggregate, adopting embryonic-like properties, and finally, form a papilla condensate-like 3D spheroidal clumps. The 3D patterned DP cells maintain trichogenicity $[9,13-18]$ and can retain this inductivity in much later passages $[9,11]$. However, human $[9,19,20]$ and canine DP cells $[21,22]$ show striking different 
growth patterns under the same culture conditions. They maintain 2D growth pattern, which normally loses the ability to induce hair follicles after a few passages. Similarly, sika deer (Cerous nippon) DP cells do not aggregate spontaneously but maintain 2D growth patterns in the conventional medium [23]. Whether the loss of self-aggregative behavior relates to species-specific differences or improper culture conditions remains elusive. Previous studies tried to restore the lost key inductive properties of the fixed 2D-pattern human DP cells through adding additional inducing entities [11,18,24-27] or forcing the DP cells into a 3D state $[9,19]$. Whether the fixed 2D patterned DP cells can recover the self-aggregative behavior is unclear. In the present study, we proved it was the culture condition that determined sika deer DP cell growth pattern. We further detected the two growth patterns could transit mutually as the culture condition was exchanged. The fixed 2D patterned sika deer DP cells could recover the self-aggregative behavior and transit back to 3D pattern with restored hair inducing capability. To further reveal the mechanism behind the transition, an RNA-seq based transcriptome analysis was conducted to compare gene expression patterns between the fixed 2D patterned DP cells (UDP), the re-aggregating DP cells (MDP) and the restored 3D patterned DP cells (ADP). The candidate genes and regulating pathways contributing to the recovery of the $3 \mathrm{D}$ pattern and the hair inducing capability were predicted and verified through real-time PCR analysis.

\section{Results}

\subsection{Sika Deer Dermal Papilla Cell Culture}

The DP tissues were isolated from individual furs from 15 sika deer for primary culture (Figure 1A,B). Spindle-shaped DP cells began to migrate out from the attached DP within 3-5 days (Figure 1C). The intact papillae eventually collapsed when the dish was approaching $60 \%$ confluence on the 8 th day on average (Figure 1D). The sub-cultured DP cells of the first two generations in DMEM/deer serum showed monolayer growth-pattern with flattened, polygonal, and fibroblastic morphology and maintained the pattern for the rest passages (Figure 1E). Though in rare cases, some sub-cultured DP cell lines maintained the self-aggregative behavior and finally formed the 3D pattern after reaching confluence (less than $5 \%$ ), the whole process is time consuming-normally lasting for one month and the aggregative behavior is soon lost in two generations.

\subsection{Restoration of 3D-Pattern DP Cells from Fixed 2D Patterned DP Cells}

After sub-culturing the selected three 2D patterned DP cell lines for two passages in $2 \mathrm{D}$ culture conditions, the $2 \mathrm{D}$ pattern was fixed. We first tried to change the $2 \mathrm{D}$ culture condition into a 3D-culture condition for the fixed 2D patterned DP cells from different passages. The results showed the recovery duration of the self-aggregative behavior correlated with the fixed time in 2D pattern. The second or third 2D patterned DP cell passage normally recovered the self-aggregate behavior in $24-48 \mathrm{~h}$ (Figure $1 \mathrm{~F}$ ) and grew into 3D spheroids in 3 days (Figure $1 G$ ) after the 3D-culture condition was applied. The spheroids were 100-200 $\mu \mathrm{m}$ in diameter on average. However, the 2D patterned DP cells over the fifth passage did not recover the self-aggregative behavior in the first two passages when the 3D-culture condition was applied. They kept 2D flattened morphology but had faster proliferating speed in the first passage (Figure $1 \mathrm{H}$ ) compared to those continually sub-cultured in 2D-culture conditions. The self-aggregative behavior appeared in the second passage after the 3D condition was applied, as the DP cells reached confluence (Figure 1I). Though 3D pattern could not form in most cases in this passage. Until the third passage after the 3D condition applied, the DP cells restored the 3D spheroidal appearance once they attached to the surface of the culture dish (Figure 1J). The restored 3D pattern would retain for the rest passages under 3D-culture condition. On the contrary, when the culture condition of fixed 3D patterned DP cells was changed into the 2D-culture condition, DP cells no matter how long they had been cultured in 3D-culture conditions would lose their behavior in one passage. The results of CCK-8 assay showed 2D-pattern DP cells had more rapid cell expansion than restored 3D-pattern DP cells in general (Figure 1K). When 
ADP began to aggregate on the first day and second day after seeding, their proliferation rates were slightly higher than UDP $(p<0.05)$. However, after the spheroids formed on the third day, the growth rate of ADP became moderate, whereas UDP reached their logarithmic phase, showed robust expansion. The growth rate of UDP kept significantly higher than those of ADP since the 4th day $(p<0.01)$.

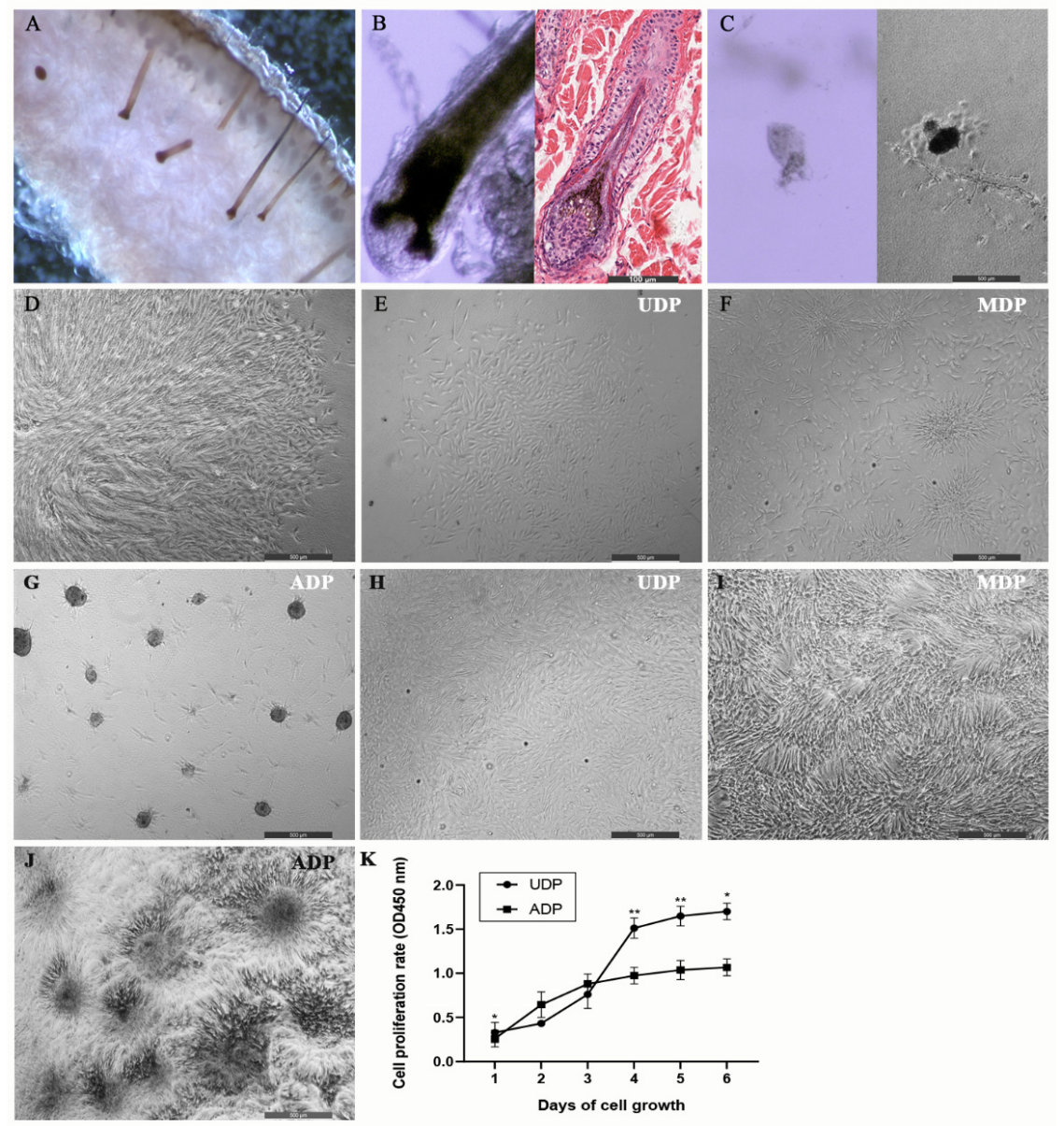

Figure 1. Sika deer dermal papilla isolation, cell culture, and cell proliferation test. (A) A slide of back skin is divided into strips around $0.5 \mathrm{~cm}$ in width and $1 \mathrm{~cm}$ in length along the longitudinal axis. (B) Bar $=100 \mu \mathrm{m}$. Isolated sika deer fur follicle (left) and longitudinal section of the sika deer fur follicle with HE staining (right). (C-J): bar $=500 \mu \mathrm{m}$. (C) Dissociative dermal papilla (DP) tissue sticks on the culture plate surface (left) and DP cells begin to migrate out from the attached DP tissue in primary culture (right). (D) The intact papillae eventually collapses when the dish is approaching $60 \%$ confluence in primary culture. (E) The sub-culture DP cells in 2D culture condition show 2D monolayer-growth pattern: flattened, polygonal, and fibroblastic morphology. (F) The sub-culture DP cells of the second passage begin to aggregate in 24-48 $\mathrm{h}$ when they are changed into 3D culture conditions. (G) The sub-culture DP cells of the second passage in 3D culture condition finally grow into 3D spheroidal pattern in 3 days (average diameter $=100-200 \mathrm{~nm}$ ). $(\mathbf{H})$ The sub-culture 2D patterned DP cells of the fifth passage kept 2D flattened morphology when they were cultured in 3D-culture condition for first passage. (I) The self-aggregative behavior begins to appear in the second passage after the medium transition, as the DP cells reach confluence under 3D-culture conditions. (J) The spheroidal appearance restores once DP cells attach the surface of the culture dish in the third passage under 3D-culture condition. (K) Comparison of cell proliferation between fixed 2D patterned DP cells (UDP) and restored 3D patterned DP cells (ADP) through paired t test. Cells (2000/well) are seeded and the proliferative rates were assessed using Cell Counting Kit- 8 on the 1st, $2 \mathrm{nd}, 3 \mathrm{rd}, 4 \mathrm{th}, 5$ th, and 6 th days. $Y$-axis represents the $\mathrm{OD}$ values at a wavelength of $450 \mathrm{~nm}$. $X$-axis represents the period of cell growth. ${ }^{*} p<0.05,{ }^{* *} p<0.01$. 
2.3. Identification of Hair Inducing Activity through Specific Expression of CD133, SOX2, Versican, and ALPL on DP Cells

CD133 and versican are two important makers of hair follicle-inducing capability in vivo $[16,28,29]$. Our results showed UDP did not express CD133 (Figure 2A) or versican (Figure 2D). MDP became CD133/versican positive as the culture condition changed (Figure 2B,E), and CD133 showed much lower expression level compared to versican in MDP. Both markers showed a high expression intensity in ADP (Figure 2C,F). The results confirmed that UDP lost hair-inducing capability. When DP cells restored aggregation, their hair-inducing capability gradually restored and reached the strongest level when spheroids formed.

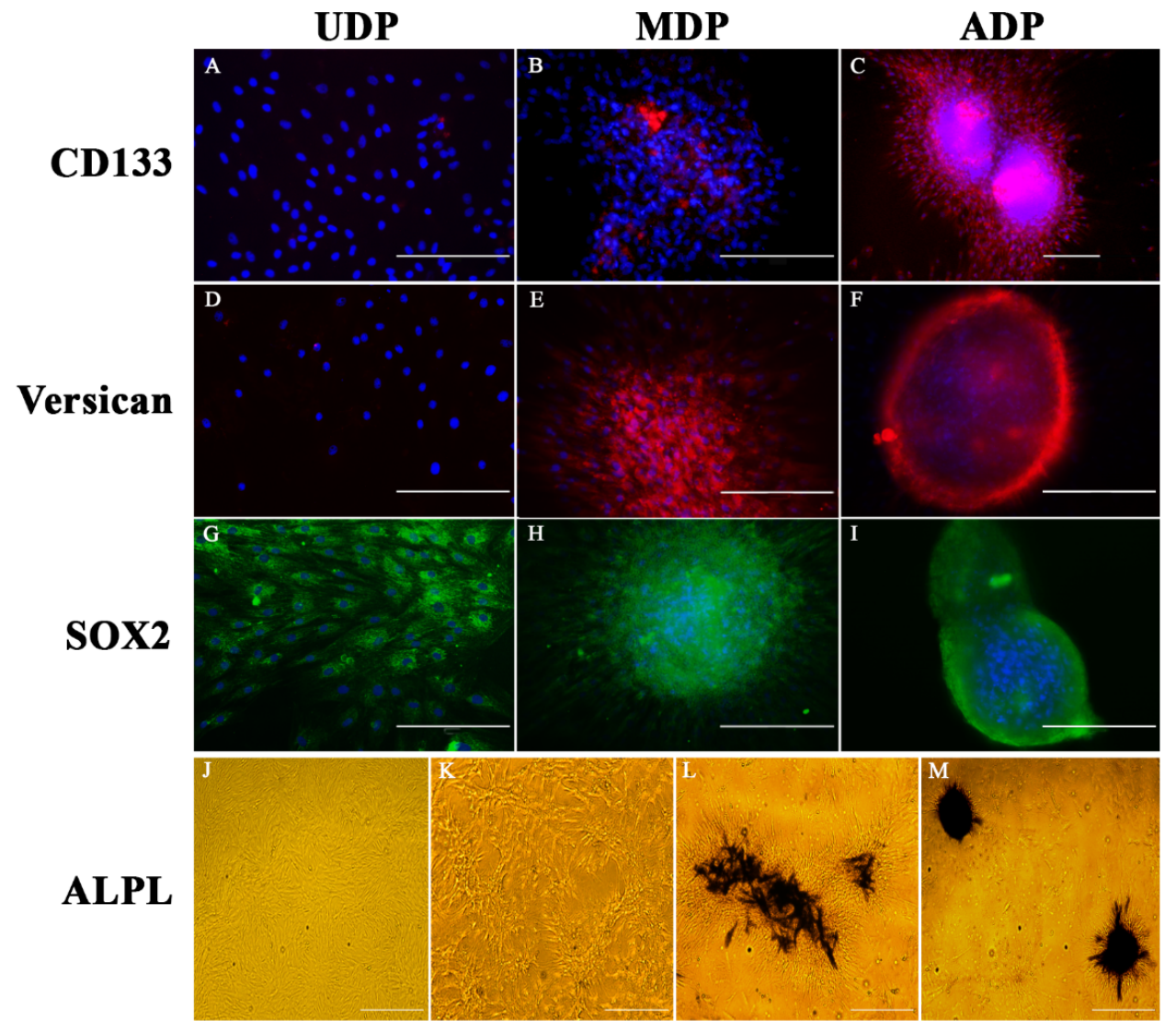

Figure 2. Identification of hair inducing capability of cultured DP cells. Bar $=200 \mu \mathrm{m}$. Comparison of immunofluorescence staining of CD133 (A-C), versican (D-F), SOX2 (G-I) and alkaline phosphatase (ALPL, J-M) on fixed 2D patterned DP cells (UDP), the re-aggregating DP cells (MDP) and restored 3D patterned DP cells (ADP). (A) UDP do not express CD133 (red) and DAPI (blue) marks all cell nuclei. (B) CD133 begins to express in MDP, but the expression intensity is weak (red). (C) ADP show strong CD133 expression intensity. (D) UDP do not express versican (red) and DAPI (blue) marks all cell nuclei. (E) Versican begins to express in MDP and the expression intensity is strong. (F) ADP continually show strong versican expression intensity. (G) UDP have strong expression intensity of SOX2 (green) and DAPI (blue) marks all cell nuclei. (H) The expression intensity of SOX2 (green) keeps strong in MDP. (I) ADP continually keep strong SOX2 expression (green). (J-M): bar $=500 \mu \mathrm{m}$. Comparison of Alkaline phosphatase (ALPL) staining during the process of ADP formation. (J) UDP do not show the ALPL staining. (K) DP cells do not express ALPL when they begin to aggregate. (L) MDP express strong expression of ALPL. (M) The ALPL expression reaches highest intensity in ADP.

Sox 2 is an important indicator of the stem cells which are important for tissue regeneration [30]. In pelage hair follicles, Sox 2 also functions as specifying the hair types [28,31,32]. In postnatal skin, Sox 2 is only expressed in the DP of guard/awl/auchene follicles, whereas 
DP of the zigzag follicle is Sox 2 negative [32]. Our results showed UDPs were Sox 2 positive (Figure 2G). When the culture condition was changed, MDP and ADP continually kept the strong SOX2 expression (Figure $2 \mathrm{H}-\mathrm{I}$ ). The findings confirmed the stem cell identity of the cultured DP cells. Unlike versican and CD133, Sox2 expression in DP was an intrinsic property, unrelated to morphological change or hair inducing capability.

Alkaline phosphatase (ALPL) activity correlates closely with DP trichogenicity, but its changing pattern was mainly studied on DP tissues during hair cycle [18,33,34]. Our study first visualized the change of ALPL staining pattern in DP cells. According to the results, UDP did not express ALPL (Figure 2J). When DP cells began to aggregate as the culture condition changed, they did not express ALPL (Figure 2K) until MDP phase (Figure 2L). The ALPL expression reached the highest intensity in ADP phase (Figure 2M). The results further confirmed UDP lost hair-inducing capability, which is restored as DP self-aggregation reformed.

\subsection{Transcriptome Analysis Revealed Important Genes Contributing to Restored 3D Pattern}

To reveal the regulating genes in transition from UDP to ADP, we conducted RNA-seq analysis on UDP, MDP, and ADP. The hierarchical clustering was performed on the transcript signatures of UDP, MDP, and ADP. The results showed MDP and ADP independently clustered together (Figure 3D), whereas UDP from each donor were clustered. In addition, we calculated the correlation among UDP, MDP, and ADP (Figure 3C). The average correlation coefficient between ADP and MDP was 0.98 (range: 0.97-0.98), whereas between ADP and UDP it was 0.82 (range: $0.82-0.83$ ), and between MDP and UDP, it was 0.83 (range: 0.826-0.829). Furthermore, in PCA analysis (Figure 3A), compared to PC2, PC1 explained $70.12 \%$ of the overall variation so that it could represent the overall trend. The distance between ADP and MDP was significantly shorter than that between MDP and UDP in PC1. The results of the three analyses together suggested compared to UDP, MDP showed a more similar gene expression pattern with ADP. The distinctive expressed gene patterns between UDP and MDP, ADP related to aggregative behavior.

The results of Venn analysis showed 267 DEGs between MDP and UDP, 327 DEGs between MDP and ADP, and 576 DEGs between ADP and UDP (Figure 3B, log2foldchange I $\geq 2$, adjusted $p$ value $\leq 0.05$ ). Among them, 11 co-expressed DEGs in UDP, MDP, and ADP were further detected, including 6 gradually up-regulated genes and 5 gradually down-regulated genes ( $\mid \log 2$ foldchange $\mid \geq 2$, adjusted $p$ value $\leq 0.01$, Table 1 ). In view of the similar expression between ADP and MDP, 576 DEGs between ADP and UDP were selected for further analysis. The DEGs included 317 up-regulated genes and 259 down-regulated genes of ADP compared to UDP (Figure 4C). The results of the biological process of GO enrichment analyses showed the up-regulated genes were mainly classified into the categories of cell adhesion, collagen catabolic process, extracellular matrix disassembly, cell-matrix adhesion, positive regulation of protein kinase B signaling and collagen fibril organization, etc. $(p<0.01$, Figure $4 \mathrm{~A})$. The results of cellular component of GO enrichment analyses showed the up-regulated genes were mainly classified into the categories of integral component of membrane, plasma membrane, extracellular region, extracellular space, integral component of plasma membrane, proteinaceous extracellular matrix and extracellular matrix, etc. ( $p<0.01$, Figure $4 B)$. Furthermore, the up-regulated genes of UDP compared to ADP enriched in biological process of GO terms were mainly related to cell proliferation, cell division, and regulation of cell cycle, etc. $(p<0.01$, Figure 4D). The up-regulated genes of UDP compared to ADP enriched in cellular component of GO terms were mainly related to extracellular region, extracellular space, neuronal cell body, and extracellular matrix $(p<0.01$, Figure 4 F). The KEGG pathway analysis of all DEGs between ADP and UDP mainly included pathways in PI3K-Akt signaling pathway, proteoglycans in cancer, neuroactive ligand-receptor interaction, focal adhesion, protein digestion and absorption, cytokine-cytokine receptor interaction, ECM-receptor interaction, Hippo signaling pathway, and cGMP-PKG signaling pathway ( $p<0.05$, Figure $4 \mathrm{E})$. The gene network of ECM-receptor interaction pathway was mapped to detect the specific regulating process (Supplementary Figure S1). 
A

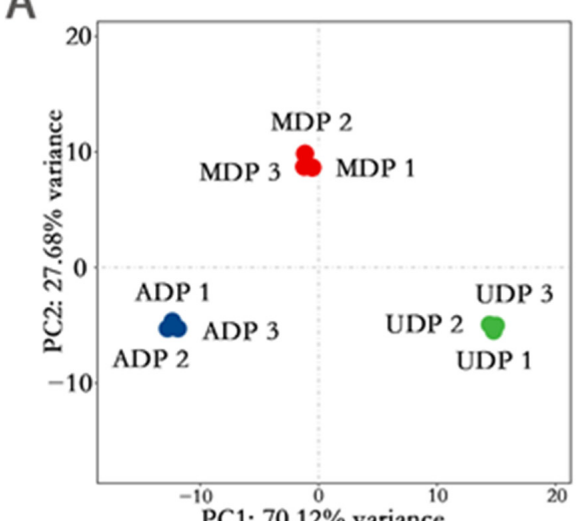

C

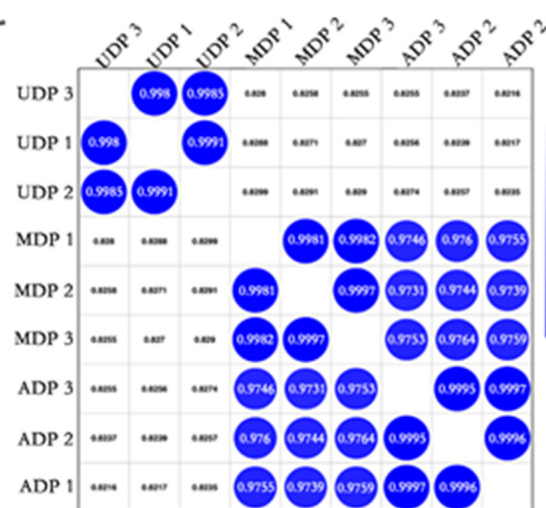

$\mathrm{E}$
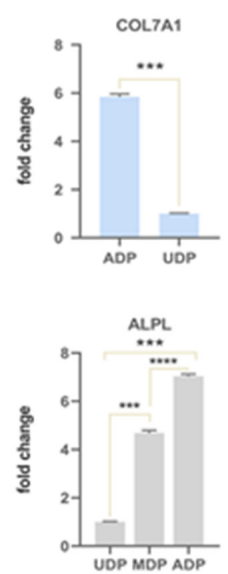

B

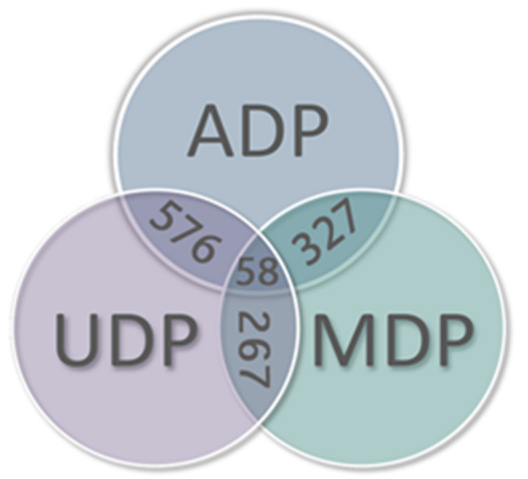

D
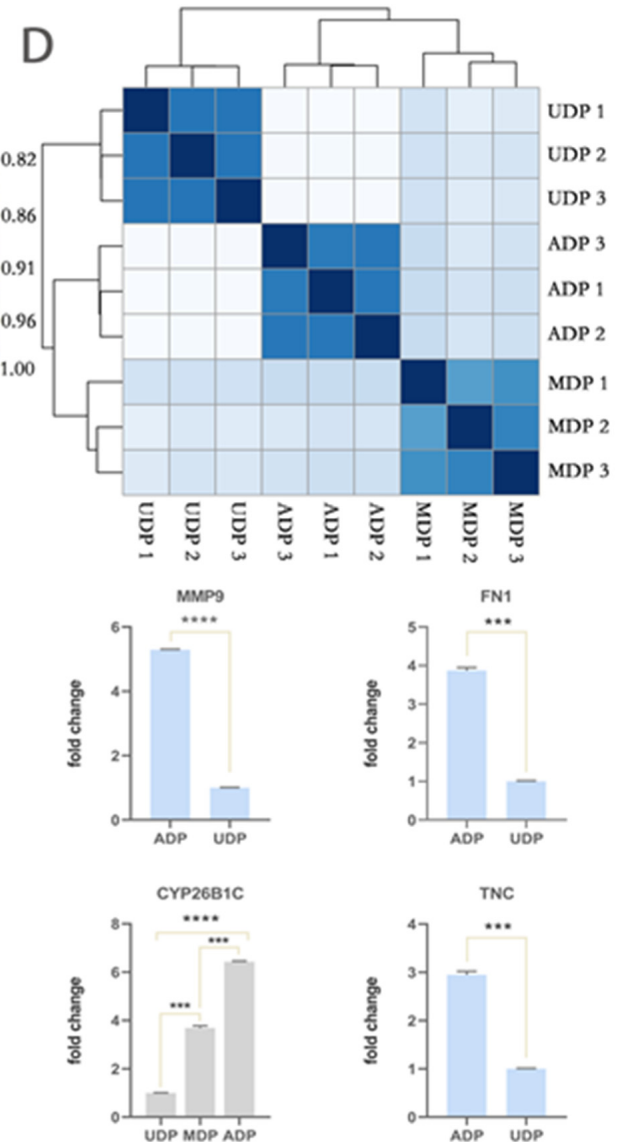

Figure 3. A general view of gene expression pattern and RT-PCR verification on selected DEGs. (A) The PCA analysis is performed on the transcript signatures of fixed 2D patterned DP cells (UDP), the re-aggregating DP cells (MDP), and restored 3D patterned DP cells (ADP). PC1 explained 70.12\% of the overall variation. The distance between ADP and MDP is significantly shorter than that between MDP and UDP in PC1. (B) Venn analysis is performed on differentially expressed genes (DEGs) of UDP, MDP, and ADP. In total, 267 DEGs are expressed between MDP and UDP, 327 DEGs are expressed between MDP and ADP and 576 DEGs are expressed between ADP and UDP ( $\mid \log 2$ foldchange $\mid \geq 2$, adjusted $p$ value $\leq 0.05)$. Among them, 11 co-expressed DEGs in UDP, MDP, and ADP are further selected $(\mid \log 2$ foldchange $\mid \geq 2$, adjusted $p$ value $\leq 0.05$ ). (C) The correlation analysis is performed on the transcript signatures of UDP, MDP, and ADP. The average correlation coefficient between ADP and MDP is 0.98 (range: 0.97-0.98), whereas between ADP and UDP is 0.82 (range: 0.82-0.83) and between MDP and UDP is 0.83 (range: 0.826-0.829). (D) The hierarchical clustering analysis is performed on the transcript signatures of UDP, MDP, and ADP. Compared to UDP, MDP and ADP independently cluster together. (E) Verification of transcriptome results on the selected DEGs (RT-PCR, three individual wells/cell type) during the process of ADP re-formation, ${ }^{*} p<0.05,{ }^{* * *} p<0.001,{ }^{* * *} p<0.0001$ (paired $t$-test). 


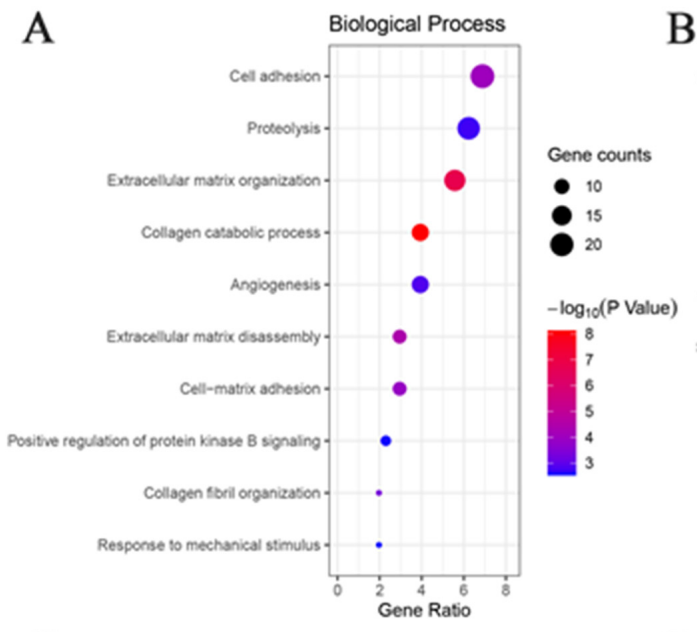

$\mathrm{C}$

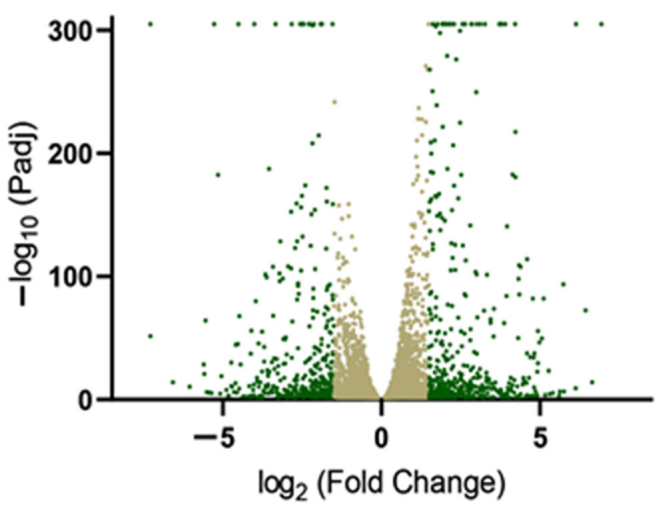

$\mathrm{E}$

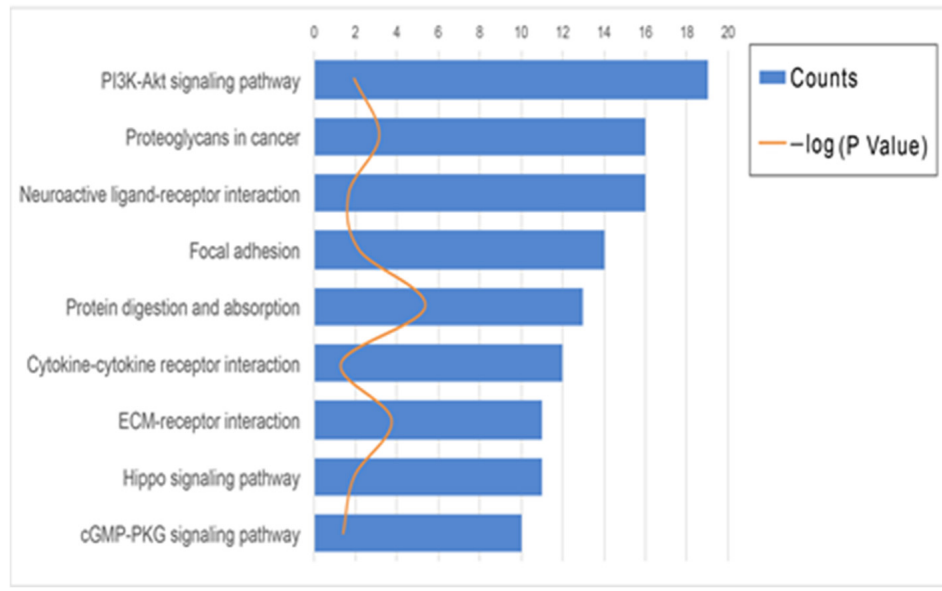

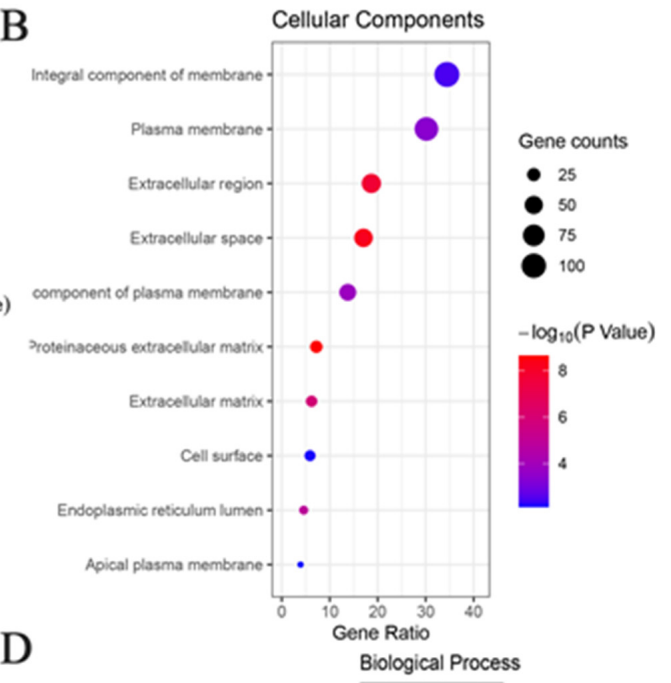
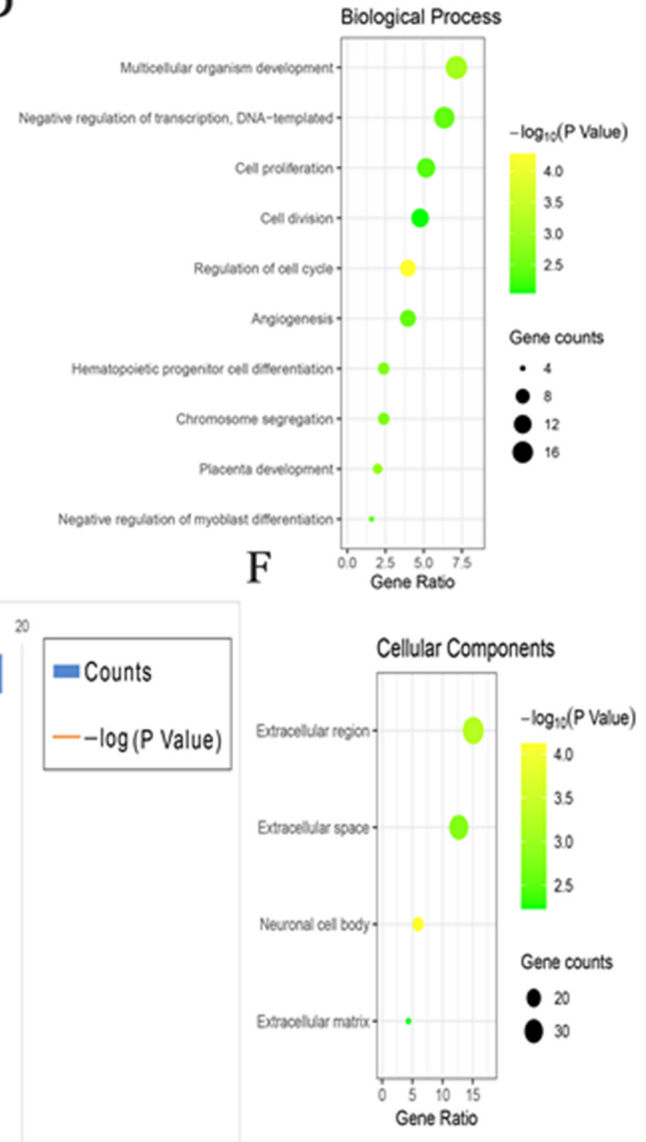

Figure 4. GO and KEGG analysis on DEGs between ADP and UDP. (A) GO analysis in BP is performed on the 214 upregulated DEGs of ADP compared to UDP. The vertical axis represents the top 10 ranked GO terms according to the gene counts. The different colors from blue to red represent the $-\log 10$ of adjusted $p$ values (adjusted $p$ values $<0.01$ ). The horizontal axis represents gene ratio, which is the percentage of total DEGs in the given GO term. (B) GO analysis in CC is performed on the 214 up-regulated DEGs of ADP compared to UDP. The vertical axis represents the top 10 ranked GO terms according to the gene counts. The different colors from green to yellow represent the $-\log 10$ value of adjusted $p$ values (adjusted $p$ values $<0.01$ ). The horizontal axis represents gene ratio, which is the percentage of total DEGs in the given GO term. (C) Volcano plot shows the expression level of DEGs between ADP and UDP. X-axis represents the log2 fold change 
values of DEGs between ADP and UDP. The values $\geq 2$ or $\leq-2$ are marked by green color. $Y$-axis denotes $-\log 10$ value of adjusted $p$ value (padj) of DEGs, padj < 0.01. (D) GO analysis in BP is performed on the 113 down-regulated DEGs of ADP compared to UDP. The vertical axis represents the top 10 ranked GO terms according to the gene counts. The different colors from blue to red represent the $-\log 10$ of adjusted $p$ values (adjusted $p$ values $<0.01$ ). The horizontal axis represents gene ratio, which is the percentage of total DEGs in the given GO term. (E) KEGG pathway analysis is performed on all DEGs between ADP and UDP. The blue bars of $X$-axis denote the gene counts of enriched KEGG pathway categories. The orange curve denotes the $-\log 10$ values of adjusted $p$ values on enriched KEGG pathway categories, adjusted $p$ value $<0.05$. $Y$-axis represents the enriched KEGG pathway categories of all DEGs between ADP and UDP. (F) GO analysis in CC is performed on the 113 down-regulated DEGs of ADP compared to UDP. The vertical axis represents all 4 ranked GO terms according to the gene counts. The different colors from green to yellow represent the $-\log 10$ value of adjusted $p$ values (adjusted $p$ values $<0.01$ ). The horizontal axis represents gene ratio, which is the percentage of total DEGs in the given GO term. GO, gene ontology; BP, biological process; CC, cellular component; ADP, restored 3D patterned DP cells; UDP, fixed 2D patterned DP cells; DEG: differentially expressed genes. Gene counts: the number of genes enriched in a GO term, represented by the different sizes of the circles.

\subsection{Real-Time PCR Analysis Verified Transcriptome Results}

Five up-regulated DEGs of ADP compared to UDP (COL4A5, COL7A1, MMP9, FN1, TNC) were selected and validated by RT-PCR. The results showed that the expression levels of those genes were significantly higher in ADP than UDP $(p<0.01)$. In addition, three co-expressed DEGs from UDP, MDP, and ADP (ALPL, Cyp26b1c, CHRDL1) were validated by qRT-PCR as well. The expression levels of ALPL and Cyp26b1c significantly increased along with UPD, MDP, and ADP $(p<0.01)$ (Figure 3E). The expression level of CHRDL1 significantly decreased along with UPD, MDP, and ADP $(p<0.01)$. The q-PCR results were the same as RNA-seq results.

Table 1. The 11 co-expressed DEGs ${ }^{\dagger}$ in UDP, MDP, and ADP $\ddagger$, including six gradually up-regulated genes and five down-regulated genes ( $\mid \log 2$ foldchange $\mid \geq 2$, adjusted $p$ value $\leq 0.01$ ).

\begin{tabular}{|c|c|c|c|c|}
\hline Gene ID & Gene Name & Gene Symbol & $\begin{array}{l}\text { Log2FoldChange } \\
\text { ADP vs. MDP }\end{array}$ & $\begin{array}{l}\text { Log2FoldChange } \\
\text { MDP vs. UDP }\end{array}$ \\
\hline Celaphus_00014740 & Alkaline phosphatase, tissue-nonspecific isozyme & ALPL & 2.1 & 4.3 \\
\hline Celaphus 00011342 & Liprin-alpha-2 & Ppfia2 & 2.2 & 2.8 \\
\hline Celaphus_00005746 & Cytochrome P450 26B1 & CYP26B1 & 2.2 & 2.1 \\
\hline Celaphus_00011343 & Liprin-alpha-4 (Fragment) & Ppfia4 & 2.7 & 2.1 \\
\hline Celaphus_00008669 & $\begin{array}{l}\text { Disintegrin and metalloproteinase } \\
\text { domain-containing protein } 8\end{array}$ & ADAM8 & 3.7 & 2.1 \\
\hline Celaphus_00001834 & SLAM family member 8 & SLAMF8 & 2.13 & 2.12 \\
\hline Celaphus_00005340 & Kelch-like protein 29 & KLHL29 & -4.2 & -2.4 \\
\hline Celaphus_00012937 & $\begin{array}{l}\text { Solute carrier organic anion transporter } \\
\text { family member } 2 \mathrm{~A} 1\end{array}$ & Slco2a1 & -2.2 & -2.5 \\
\hline Celaphus_00009791 & Chordin-like protein 1 & CHRDL1 & -2.7 & -2.6 \\
\hline Celaphus_00013117 & Insulin-like growth factor II & IGF2 & -5.8 & -3.1 \\
\hline Celaphus_00001878 & Platelet endothelial aggregation receptor 1 & PEAR1 & -3.8 & -3.5 \\
\hline
\end{tabular}

${ }^{\dagger}$ DEGs: differentially expressed genes; $\ddagger$ UDP: fixed 2D patterned DP cells, MDP: the re-aggregating DP cells, ADP: restored 3D patterned DP cells.

\section{Discussion}

DP cells of several species, including human, maintain 2D pattern under conventional culture conditions, accompanied by the loss of hair inductive competence $[9,35]$. Whether the self-aggregative behavior is a species-specific capability and will the loss of the selfaggregative behavior be recovered remain unclear. In view of DP tissue as a specialized mesenchymal condensation [1], we considered using MSC medium to replace the conventional serum-containing culture medium for retaining the stemness maximumly. The results met our expectations and our study proved the sika deer DP cells in fixed 2D pattern could recover the spontaneous aggregation and 3D pattern with restored hair inductivity when the MSC medium was applied. It has been confirmed the expansion of mesenchymal stem cells strongly depends on the culture condition. Compared to the medium supplemented with 10-20\% FBS, serum-free medium can better preserve the original morphology, function, and multipotentiality of the MSCs [36]. Our results suggested the spontaneous 
aggregation of DP cells was not a species-specific behavior, but closely correlated with the culture environment. It was more like to be lost under the stemness-suppression environments. When the suppression was released, the self-aggregative behavior would be recovered. It would be intriguing to try the same culture condition on human DP cells. Another interesting finding during the transition was the different proliferation rates between ADP and UDP. ADP showed a significantly lower proliferation compared to UDP according to the results of CCK8 test and transcriptome comparison. This finding was the same as the studies using DP cells from other species, which proved cultured aggregating DP cells had undergone comparatively few divisions and remained in low mitotic activity [20,37-39]. During the natural hair cycle, DP demonstrated the same low proliferative activity once established during embryonic development $[40,41]$. Our finding gave more proof that 3D-pattern DP cells more resembled natural DP behavior compared to 2D-pattern DP cells. The neogenesis of the hair follicles can be achieved by transplanting cultured ADP to the sub-epidermal space [24,42]. However, cell transplanting recipe for adult human hair-follicle neogenesis on a bald scalp has long been hampered by insufficient ADPs due to their low proliferation rate [43]. The rapid DP cell expansion in 2D pattern can theoretically be used for large-scale production of DP cells as seed bank. 3D-pattern DP cells can be induced once needed so that to resolve the insufficient ADPs in clinics.

For further detecting the mechanism behind this spontaneous transition, we performed global profiling of UDP and ADP. Previous studies proved the self-assembly of dispersed cells into 3D pattern or 2D pattern on biomaterials was switchable [44-47]. The formation of 3D pattern mainly depends on two factors: rate of cell collision and intercellular adhesion, following migration-collision-aggregation process [43,47-50]. The ultrastructural study [51] and microarray study on DP [52] both suggested cell adhesion contributed to DP aggregation. Another study found the formation of DP spheroids could be enhanced by specific coating proteins increased cell-cell adhesive strength while simultaneously maintaining high cell motility. On the contrary, the dispersed DP cells would not be able to aggregate if they cannot translocate to collide and adhere to each other [47]. Our results showed the largest amount of up-regulated genes of ADP compared to UDP was enriched in the GO term of cell adhesion, which gave more proof that cell adhesion played a vital role in DP cell aggregation. During natural hair development, the dispersal of condensates leads to papilla miniaturization and finally the disruption of hair-follicle morphogenesis [53]. Preventing the dispersal process through enhancing DP cell adhesion may offer a new strategy for treating androgenetic alopecia. Among the up-regulated genes in ADP relating to cell adhesion, fibronectin (FN1) may play an important role. FN1 coded fibronectin is an adhesive glycoprotein, which is associated with cell adhesion and migration [54,55]. FN1 locates in the extracellular matrix of DP from the embryonic stage [56,57]. Blocking of FN1 leads to the interruption of epithelial-mesenchymal interaction and cell proliferation [58]. During the pelage hair cycle, FN1 is prevalent in the DP during anagen but is lost in catagen and telogen [59]. In vitro, FN1 coating is reported to significantly increase the number of DP spheroids through increasing DP cell adhesion and maintaining high cell motility simultaneously [47]. Our results showed the expression of FN1 significantly increased in ADP compared to UDP. It may function as recruiting new cells (in vitro neighbor DP cells/in vivo connective tissue sheath cells) to migrate, collide and adhere to each other to form DP aggregation. Tenascin (TNC) is another important gene relating to cell adhesion, which encodes hexameric glycoprotein [60]. TNC refers to mesenchymal cell aggregation [61]. During the estimated gestational stage, it appears initially as focal deposits on the mesenchymal side of the dermal-epidermal junction during estimated gestational stage $[58,60,62,63]$. The follicle pre-germs develop subsequently at deposit sites. During the development of hair follicle TNC remains intensely in follicle basement membrane zone, interfollicular basement membrane zone, follicle health ECM and DP [64]. Our results suggested the TNC significantly up-regulated in ADP compared to UDP. It may contribute to promoting DP aggregation through increasing cell adhesion. 
Furthermore, we are intrigued by detecting the molecular mechanism behind the restored hair inducing capability contributed by the 3D spheroidal pattern. The results of GO analysis in biological process and cellular component both suggested most of the categories enriched by up-regulated genes of ADP compared to UDP correlated with extracellular matrix (ECM) metabolism. This finding was consistent with a study on human DP spheres [9]. ECM serves an important role in tissue and organ morphogenesis and in the maintenance of cell and tissue structure and function [65]. In natural hair development, ECM is produced far before hair follicle morphogenesis by pre-follicular tissue. Early in the embryonic-fetal transition phase of gestational age, various ECM molecules are produced to concentrate beneath the basal lamina of the embryo, which cause the basement membrane to appear thickened and gradually form a broader, second sub-epidermal zone of dermis, referred to as compact mesenchyme. As the mesenchyme cells begin to aggregate to form condensed mesenchyme- DP precursors, some of the ECM molecules distributed generally throughout the compact mesenchyme prior to follicle initiation become restricted in distribution to DP [57]. During the hair cycle, the volume of ECM changes periodically with DP cell numbers. At the onset of anagen, DP displays synthetic activity and becomes separated by increasing ECM along with increased DP cells mainly compensating by connective tissue sheath cells [66]. The volume of the ECM reaches the largest amounts at the end of anagen [66], then are progressively reduced by decreased DP cell numbers during catagen, and are finally poorly developed by minimal DP cells on telogen [13]. In a study of de novo hair generation, the sub-dermal injection of ADP initially formed a papillae condensate-like clump that synthesizes its own ECM [12] ECM produced by DP is mainly related to direct matrix keratinocytes to differentiate into distinct follicular layers during the hair cycle [67]. Therefore, we can reasonably speculate that accumulated ECM would be the key step in restoring hair inducing capability of 3D-pattern DP cells. ECM is a complex mixture of matrix molecules, involving various metabolic processes. Previous studies identified several molecules of the ECM produced by DP, but they were detected individually [39]. Our study first offered a general view of ECM relevant genes up-regulated in 3D-pattern DP cells compared to 2D-pattern DP cells, including cell-matrix adhesion, extracellular matrix organization, extracellular matrix disassembly, collagen catabolic process, and collagen fibril organization. We additionally identified specific gene signaling pathways involving ECM metabolic processes, including ECM-receptor interaction, focal adhesion, and PI3K-Akt signaling pathway. The genes and signaling pathways may help to uncover the specific functions of ECM in hair restoring ability of 3D cultured DP cells.

Among the up-regulated ECM genes, genes from the collagen family and matrix metalloproteinases $(M M P s)$ family took high proportion. Collagens play structural roles and contribute to mechanical properties, organization, and shape of tissues, whose superfamily comprises 28 members in vertebrates [68]. Collagen I, III, IV has been widely reported to express in DP [57,69]. Our results suggested the expressions of those collagen encoding genes were up-regulated in 3D-pattern DP cells compared to 2D-pattern DP cells. Besides, COL5A3, COL7A1, COL11A2, and COL27A1 showed the same expression pattern. COL7A1 encoding collagen VII can be assembled into anchoring fibrils [70-72]. COL27A1 encoding collagen XXVII forms $10 \mathrm{~nm}$ nonstriated fibrils [73]. Different collagens can also be comprised into collagen fibrils based on their supramolecular assemblies and the cross-linking is tissue-specific [74]. GO results suggested the collagen fibrils formed in DP aggregation included COL1A2 encoding collagen I, COL3A1 encoding collagen III, COL5A3 encoding collagen $\mathrm{V}$ and COL11A2 encoding collagen XI. The assembled fibrils may undertake the mechanical properties that offer a stable environment for the interactions between cells and ECM. MMPs are the main group of enzymes responsible for the collagen degradation in ECM, involving in the processes of proteolysis, collagen catabolic process, and extracellular matrix disassembly [75,76]. We detected that MMP9, MMP13 MMP15, MMP16, and $M M P 19$ were up-regulated in ADP compared to UDP. Among them, MMP-13 preferential 
cleaves collagen II [77], whereas collagen IV is the preferential substrate of MMP-9 [78]. $M M P-15$ and MMP-16 are reported to increase cell adhesion [76].

We additionally identified co-expressed DEGs in UDP, MDP, and ADP, including Cyp26b1, CHRDL1, ALPL, and ADAM8. The expression of Cyp26b1c increased along with DP aggregation. Cyp26b1c is one of the retinoic acid (RA)-degrading enzymes of the cytochrome P450 26 subfamily, which is specifically expressed in the dermis surrounding the developing hair follicles [79,80] and DP [81]. Excess RA has been shown to induce catagen-like hair follicle regression [82,83]. The ablation of Cyp26b1 in embryonic period leads to excessive endogenous RA, resulting in the arrest of hair follicle growth at the hair germ stage, which can be rescued by the normalization of RA level. The conditional deficiency of Cyp26b1 in the dermis also leads to excessive endogenous RA resulting in decreasing hair follicle density and a specific effect on hair bending [81]. The up-regulated Cyp26b1c along with DP aggregation may function as degrading RA so that to promote follicle growth. The ALPL is another important gene that showed significantly increased expression during DP aggregation. The recovery of hair inductivity is accompanied by restoration of ALPL expression in DP cells $[9,20,84,85]$. In the pelage follicles, AP activity is constantly and uniformly detected in the DP during the hair cycle [33], whereas in vibrissal follicles it dynamically changes, peaking in the early anagen phase [34]. In cell culture, majority primary-cultured DP cells express ALPL during the first few days, but later they began to lose ALPL expression. By the second passage, $<5 \%$ were ALPL-positive [18]. Our results of ALPL staining and transcriptome analysis both suggested sub-cultured 2D-pattern AP cells lost $A L P L$ expression. When they were reprogrammed into 3D pattern, their ALPL expression recovered and reached the highest level as spheroids formed. The results suggested the reforming ALPL in 3D-pattern DP cells might be one of the important elements contributing to follicle generation. On the contrary, the expression of CHRDL1 was decreased along with DP aggregation. CHRDL1 encodes secreted glycoprotein Chordinlike $1(\mathrm{x})$ [86]. CHRDL1 is known as a common bone morphogenetic proteins (BMP) inhibitor, sequestering the BMP in the extracellular space [86-88]. The hair follicle bulb microenvironment is rich in BMPs that act on DP cells to improve hair-inducing activity. The declined expression of CHRDL1 in DP aggregation may increase BMP signaling so that to improve hair-inducing activity. The ALPL expression is also highly specific to members of the BMP family [18]. The over-expression of BMP receptors is reported to lead to robust maintenance of AP activity in DP. The declined expression of CHRDL1 may also contribute to the increasing level of $A L P L$ through increase BMP signaling during DP aggregation.

To conclude, our study constructed two fixed growth patterns of sika deer DP cells and proved it was the culture condition that determined sika deer DP growth pattern. The two growth patterns could transit mutually as the culture condition was exchanged. The fixed 2D-pattern sika deer DP cells could recover the self-aggregative behavior and 3D pattern, accompanied by the restoration of hair inducing capacity when the appropriate culture condition was applied. We additionally offered a general view of genes and pathways regulating the transition process. Among them, cell adhesion relevant genes played important roles in the formation of aggregation. ECM metabolism relevant genes and regulating networks were essential for the restoration of hair-inducing capacity. These findings represent a significant advance on recovering DP cell function so that to lay the basis of cell transplanting therapy on hair regeneration.

\section{Materials \& Methods}

\subsection{Animals}

The skin tissues were harvested through surgical operation on 15 farmed male sika deer (Cervus nippon), with ages ranging from 2-3 years old immediately after the anesthetization in summer. After shaving the furs, the skin was sterilized through $75 \%$ ethanol and iodine solution. A $1 \times 2 \mathrm{~cm}^{2}$ [2] skin cut was made and placed into DMEM medium (11965092, Gibco, Grand Island, NY, USA) with $5 \times$ penicillin-streptomycin (03-031-5B, $\mathrm{BI}$, Beit Haemek, Israel) solution, $4{ }^{\circ} \mathrm{C}$, then taken back to the lab. The skin incision was 
surgically sewn up, coated with penicillin and streptomycin powder. Finally, the deer were relieved from anesthetization.

\subsection{Dermal Papilla Isolation}

After washing by three consecutive PBS washes, the skin was divided into strips around $0.5 \mathrm{~cm}$ in width and $1 \mathrm{~cm}$ in length along the longitudinal axis. The strips were put into the $60 \mathrm{~mm}$ Petri dishes (P5481, Sigma, Darmstadt, Germany) containing 0.2\% (w/v) collagenase D (11088858001, Roche, Agawam, MA, USA) in DMEM medium (11965092, Gibco) with $2 \times$ penicillin-streptomycin solution (03-031-5B, BI), $37^{\circ} \mathrm{C}$ for $2 \mathrm{~h}$. The surgical microdissection was used for acquiring DP tissue. The hair follicles were separated first from other tissues using a $27 \mathrm{G}$ needle and ophthalmic forceps. A slight cut was made at approximately three-quarters of the end bulb of the follicle for squeezing the DP out. After cutting through the stalk, an intact DP was transferred to a dish for primary culture.

\subsection{Establishment of DP Cell Lines}

The individual DP tissues were adhered to the base of the dish through a slight scratch using the needle. Around 6-10 DPs were cultured together in each $60 \mathrm{~mm}$ Petri dish (P5481, Sigma) containing 20\% ( $v / v)$ in-house made sika deer serum in DMEM medium (11965092, Gibco), with $1 \times$ penicillin-streptomycin solution (03-034-1B, BI). After the 15 sika deer DP primary cell lines were established, the cells were sub-cultured for two generations for obtaining more DP cells. Specifically, after approaching $60 \%$ confluence, the primary DP cells were detached using $0.08 \%$ trypsin-EDTA and cultured in 25 flasks (CLS430372, Corning $^{\circledR}$, Canton, NY, USA), containing $10 \%(v / v)$ in-house made sika deer serum in DMEM medium (11965092, Gibco, $\left.37{ }^{\circ} \mathrm{C}, 5 \% \mathrm{CO}_{2}\right)$. Half the amount of the cells from the 15 sub-cultured DP cell lines were preserved in liquid nitrogen and the rest were used for the pilot study. The formal experiments were conducted using three cell lines randomly selected from the 15 DP sub-cultured cell lines. All the cells used for the pilot study and the formal experiments were between passage two and eight. The DP cells in 2D pattern were established using DMEM medium (11965092, Gibco)/10\% FBS (10099141, Gibco), with $1 \times$ penicillin-streptomycin solution (03-034-1B, BI). The mesenchymal stem cell (MSC) medium (T310jv, Yuanpei, Shanghai, China) with $1 \times$ penicillin-streptomycin solution (03-034-1B, BI) was used for recovering the self-aggregative behavior and 3D pattern. A schematic was drawn to visualize the establishment of different DP cell growth patterns and the relevant analysis (Figure 5).

\subsection{Cell Counting Kit-8 Assay}

The comparison of cell proliferation rates between ADP and UDP was conducted using the Cell Counting Kit-8 (C0037, Beyotime, Shanghai, China) according to the manufacturer's instructions. 2000 cells from each cell pattern were seeded into each well of a 96-well plate with a volume of $100 \mu \mathrm{L}$ medium. Three biological replicates were performed for each type of cell. The 1st day, 2nd day, 3rd day, 4th day, 5th day, and 6th day were set as the test time points. After adding $10 \mu \mathrm{L} \mathrm{CCK}-8$ reagent to each well, the plate was incubated for $2 \mathrm{~h}$ at $37{ }^{\circ} \mathrm{C}$ and $5 \% \mathrm{CO}_{2}$. The absorbance of each well was measured at $450 \mathrm{~nm}$ and the optical density (OD) was determined via a microplate reader. A paired two-tailed t test was used to calculate the difference between samples and $p$ value $<0.05$ was considered as significant.

\subsection{Immunofluorescence Staining}

The cultured DP cells were fixed using $4 \%(w / v)$ paraformaldehyde fixation for $10 \mathrm{~min}$. The cells were permeabilized for 5 min using PBS with $0.3 \%$ Triton X-100 (T8787, Sigma). Blocking was performed for 30 min using $3 \%(w / v)$ bovine serum albumin in PBS. The primary antibodies including rabbit anti-CD133 (1:500; Abcam, Cambridge, MA, USA), mouse anti-SOX2 (1:200; SantaCruz, Santa Cruz, CA, USA) and rabbit anti-Versican (1:500; Bioss) left overnight at $4{ }^{\circ} \mathrm{C}$. The next day, the primary antibodies were washed off using 
three consecutive PBS washes. The secondary antibody, Alexafluor 594 goat anti-rabbit (1:1000; Thermo, Agawam, MA, USA)/ Alexafluor 488 rabbit anti-mouse (1:1000; Thermo) was applied for $1 \mathrm{~h}$ at room temperature. The nuclei of cells were counterstained with DAPI (C1005, Beyotime) for $5 \mathrm{~min}$ at room temperature after removing the secondary antibody using three consecutive PBS washes. The coverslips were mounted using antifade reagent and the cells were visualized on a Zeiss Exciter fluorescent microscope. The specific information on all the antibodies used is listed in Supplementary Table S1.

\section{Sika deer dermal papilla tissues}

2D pattern

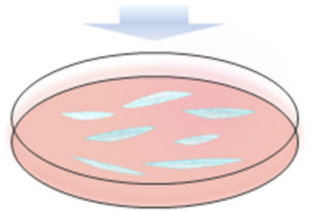

\section{Collagenase}

Dispase

\section{Primary dermal papilla cells}

DMEM/Deer serum
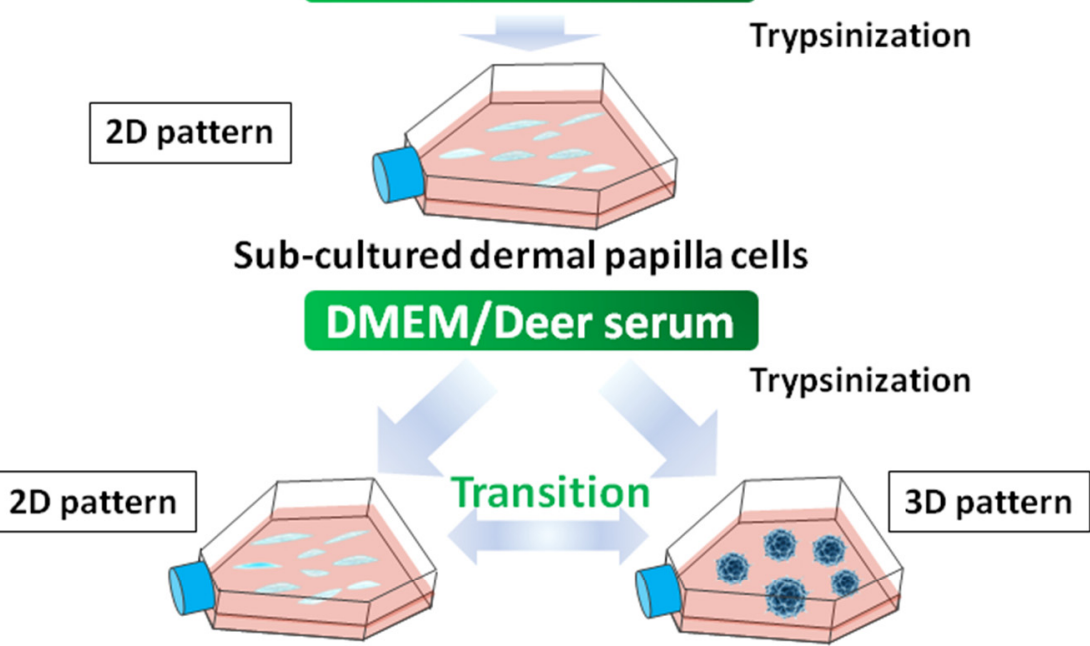

Sub-cultured dermal papilla cells

DMEM/FBS

MSC medium

Comparison

\section{CCK-8 assay, Immunofluorescence staining}

\section{Alkaline phosphatase stain, Transcriptome analysis}

Figure 5. A schematic visualized the establishment of different DP cell growth patterns and the following analysis procedures.

\subsection{Alkaline Phosphatase Stain}

The cultured DP cells were fixed using $4 \%(w / v)$ paraformaldehyde fixation for $10 \mathrm{~min}$ and washed by PBS. The cells were incubated in BCIP/NBT staining solution (Beyotime, P0321) for $4 \mathrm{~h}$ in the dark at room temperature. The reaction was stopped by washing with PBS, and the cells were examined under a bright field microscope. Dark blue staining indicates positive signal for alkaline phosphatase stain (ALPL).

\subsection{RNA Isolation and Real-Time PCR}

The cells were briefly washed three times by PBS. Total RNA was isolated and purified using RNeasy mini kit 50 (151043752, Qiagen, Germantown, MD, USA), according to the 
manufacturer's instructions. The RNA was quantified by measuring optical absorbance at $260 \mathrm{~nm}$ using Pro2000, Tecan, Switzerland and $200 \mathrm{ng}$ was reverse transcribed cDNA using PrimeScript ${ }^{\mathrm{TM}}$ RT reagent Kit (RR047A, Takara, Shiga, Japan) and oligo dT primers following the manufacturer's instructions. Real-time PCR was performed using SYBR green I Master mix (4707516001, Roche) on an Applied Biosystems 7300 Real-Time PCR System. GAPDH were used in each reaction as a baseline control. Fold changes were calculated using the delta-delta $\mathrm{CT}$ algorithm, relative to GAPDH. A paired two-tailed $t$ test was used to calculate the differences between samples and $p$ value $<0.05$ was considered as significant. Three biological replicates were performed for each gene of interest. GraphPad Prism ver. 8.2.0 (H. Motulsky, San Diego, CA, USA) was used to analyze data. The primer information is listed in Supplementary Table S2.

\subsection{Transcriptome Analysis}

Total RNA of UDP, MDP, and ADP were extracted using a Trizol reagent (Invitrogen Inc., Camarillo, CA, USA) according to the manufacturer's procedure. RNA integrity was evaluated using the Agilent 2100 Bioanalyzer (Agilent Technologies, Santa Clara, CA, USA). The samples with RNA Integrity Number (RIN) $\geq 7$ were subjected to the subsequent analysis. The libraries were constructed using TruSeq Stranded mRNA LTSample Prep Kit (Illumina, San Diego, CA, USA) according to the manufacturer's instructions. Then these libraries were sequenced on the sequencing platform (Illumina HiSeq X ten, OEbiotechCo., Ltd., Shanghai, China) and $125 \mathrm{bp} / 150$ bp paired-end reads were generated. Raw reads were processed using Trimmomatic [89]. The reads containing ploy-N and the low quality reads were removed to obtain the clean reads. The clean reads were then mapped to reference genome of Cervus elaphus hippelaphus using hisat2 [90]. The counts of the mapped reads were obtained by eXpress [91]. FPKM value of each transcript was calculated using bowtie2 [92].

\subsection{Bioinformatics Analysis on Gene Expression Pattern and Differentially Expressed Genes}

The gene expression patterns of UDP, MDP, and ADP were compared through hierarchical clustering analysis, Pearson correlation analysis, and PCA analysis. The hierarchical clustering analysis was performed used the hclust function of $R$ package stat and visualized with heatmap 2 function of $R$ package gplots [93]. The Pearson correlation analysis was performed with rcorr function of R package Hmisc [94] and visualized with corrplot R package [95]. The PCA analysis was performed using the R package prcomp and visualized by $R$ package ggplot2 [96]. The differentially expressed genes (DEGs) were identified using the DESeq R packages [97] and visualized in vacano plot using GraphPad Prism 8 (ver. 8.2.0). The adjusted $p$ value $\leq 0.05$ and $\mid \log 2$ FoldChange $\mid \geq 2$ were set as the threshold for significantly differential expression. Venn analysis was used to calculate the numbers of DEGs between different types of DP cells by excel. The GO enrichment analysis of DEGs was performed using David v6.8 [98] (https: / / david.ncifcrf.gov/, accessed on 6 March 2020) and visualized using ggplot2 $R$ package [96]. The KEGG pathway enrichment analysis of DEGs was performed using David v6.8 [98] and visualized using excel.

Supplementary Materials: Supplementary materials can be found at https:/ /www.mdpi.com/ article/10.3390/ijms22094715/s1.

Author Contributions: Conceptualization, G.W.; Methodology, G.W., H.S. and Y.Y.; Software, G.W.; Validation, G.W.; Writing—original draft, G.W.; Writing-review \& editing, G.W. Formal Analysis, G.W.; Investigation, G.W.; Resources, G.W.; Data Curation, G.W.; Writing—Original Draft Preparation, G.W.; Writing-Review \& Editing, S.Z., H.S., T.Q. and X.X.; Visualization, G.W.; Supervision, S.Z. and H.S.; Project Administration, G.W.; Funding Acquisition, H.W. and X.X. All authors have read and agreed to the published version of the manuscript.

Funding: This research was funded by the Science and Technology Development Project of Jilin Province (20180201043NY) and Youth Program of National Natural Science Foundation of China (32002321). 
Institutional Review Board Statement: The protocol and procedures employed in this study were ethically reviewed and approved according to the Animal Ethics Committee of the Institute of Special Wild Economic Animals and Plants, Chinese Academy of Agricultural Sciences (Permit Number: CAAS2015020, approved since 1 Feburary 2015).

Informed Consent Statement: Informed consent was obtained from all subjects involved in the study.

Data Availability Statement: Data is contained within the article or supplementary materials.

Acknowledgments: We thank C.Y. Li for his supports for this study.

Conflicts of Interest: The authors declare that they have no conflict of interest.

\section{References}

1. Fernandes, K.J.L.; McKenzie, I.A.; Mill, P.; Smith, K.M.; Akhavan, M.; Barnabé-Heider, F.; Biernaskie, J.; Junek, A.; Kobayashi, N.R.; Toma, J.G.; et al. A dermal niche for multipotent adult skin-derived precursor cells. Nat. Cell Biol. 2004, 6, 1082-1093. [CrossRef] [PubMed]

2. Ebling, F.J. Differentiation and Growth of Cells of the Skin. Differ. Growth Cells Vertebr. Tissues 1974, 14, 129-168. [CrossRef]

3. Jahoda, C.A.B.; Oliver, R.F.; Reynolds, A.J.; Forrester, J.C.; Gillespie, J.W.; Cserhalmi-Friedman, P.B.; Christiano, A.M.; Horne, K.A. Transpecies hair growth induction by human hair follicle dermal papillae. J. Exp. Dermatol. 2011, 10, $229-237$. [CrossRef] [PubMed]

4. Oliver, R.F. The induction of hair follicle formation in the adult hooded rat by vibrissa dermal papillae. J. Embryol. Exp. Morphol. 1970, 23, 219-236. [PubMed]

5. Pisansarakit, P.; Moore, G.P. Induction of hair follicles in mouse skin by rat vibrissa dermal papillae. J. Embryol. Exp. Morphol. 1986, 94, 113-119. [PubMed]

6. Legue, E. Hair follicle renewal: Organization of stem cells in the matrix and the role of stereotyped lineages and behaviors. Development 2005, 132, 4143. [CrossRef] [PubMed]

7. Millar, S.E. Molecular Mechanisms Regulating Hair Follicle Development. J. Investig. Dermatol. 2002, 118, 216-225. [CrossRef]

8. Ibrahim, L.; Wright, E.A. A quantitative study of hair growth using mouse and rat vibrissal follicles. I. Dermal papilla volume determines hair volume. J. Embryol. Exp. Morphol. 1982, 72, 209-224.

9. Higgins, C.A.; Chen, J.C.; Cerise, J.E.; Jahoda, C.A.B.; Christiano, A.M. Microenvironmental Reprogramming by ThreeDimensional Culture Enables Dermal Papilla Cells to Induce de Novo Human Hair-Follicle Growth. Proc. Natl. Acad. Sci. USA 2013, 110, 19679-19688. [CrossRef]

10. Rufaut, N.W.; Nixon, A.J.; Goldthorpe, N.T.; Wallace, O.A.M.; Pearson, A.J.; Sinclair, R.D. An In Vitro Model for the Morphogenesis of Hair Follicle Dermal Papillae. J. Investig. Dermatol. 2013, 133, 8. [CrossRef] [PubMed]

11. Osada, A.; Iwabuchi, T.; Kishimoto, J.; Hamazaki, T.S.; Okochi, H. Long-Term Culture of Mouse Vibrissal Dermal Papilla Cells and De Novo Hair Follicle Induction. Tissue Eng. 2007, 13, 975-982. [CrossRef] [PubMed]

12. Jahoda CA, B.; Oliver, R.F. Vibrissa dermal papilla cell aggregative behaviour in vivo and in vitro. J. Embryol. Exp. Morphol. 1984, 79, 211-224. [PubMed]

13. Ohyama, M.; Zheng, Y.; Paus, R.; Stenn, K.S. The mesenchymal component of hair follicle neogenesis: Background, methods and molecular characterization. Exp. Dermatol. 2010, 19, 89-99. [CrossRef] [PubMed]

14. Yang, C.-C.; Cotsarelis, G. Review of hair follicle dermal cells. J. Dermatol. Sci. 2010, 57, 2-11. [CrossRef]

15. Horne, K.A.; Jahoda, C.A.; Oliver, R.F. Whisker growth induced by implantation of cultured vibrissa dermal papilla cells in the adult rat. J. Embryol. Exp. Morphol. 1986, 97, 111-124.

16. Kishimoto, J.; Ehama, R.; Wu, L.; Jiang, S.; Jiang, N.; Burgeson, R.E. Selective Activation of the Versican Promoter by Epithelial- Mesenchymal Interactions during Hair Follicle Development. Proc. Natl. Acad. Sci. USA 1999, 96, 7336-7341. [CrossRef] [PubMed]

17. Weinberg, W.C.; Goodman, L.V.; George, C.; Morgan, D.L.; Ledbetter, S.; Yuspa, S.H.; Lichti, U. Reconstitution of Hair Follicle Development In Vivo: Determination of Follicle Formation, Hair Growth, and Hair Quality by Dermal Cells. J. Investig. Dermatol. 1993, 100, 229-236. [CrossRef] [PubMed]

18. Rendl, M.; Polak, L.; Fuchs, E. BMP signaling in dermal papilla cells is required for their hair follicle-inductive properties. Genes Dev. 2008, 22, 543-557. [CrossRef]

19. Kang, B.M.; Kwack, M.H.; Kim, M.K.; Kim, J.C.; Sung, Y.K. Sphere Formation Increases the Ability of Cultured Human Dermal Papilla Cells to Induce Hair Follicles from Mouse Epidermal Cells in a Reconstitution Assay. J. Investig. Dermatol. 2012, 132, 237-239. [CrossRef] [PubMed]

20. Ohyama, M.; Kobayashi, T.; Sasaki, T.; Shimizu, A.; Amagai, M. Restoration of the intrinsic properties of human dermal papilla in vitro. J. Cell Sci. 2012, 125, 4114-4125. [CrossRef]

21. Bratka-Robia, C.B.; Mitteregger, G.; Aichinger, A.; Egerbacher, M.; Helmreich, M.; Bamberg, E. Primary cell culture and morphological characterization of canine dermal papilla cells and dermal fibroblasts. Vet. Dermatol. 2002, 13, 1-6. [CrossRef]

22. Fujisawa, A.; Kobayashi, T.; Amagai, M.; Iwasaki, T.; Ohyama, M. Molecular biological and morphological charaterization for canine dermal papilla cells facilitated the evaluation of condition for in vitro expansion. World Congr. Hair Res. 2010, 19, 604-605. 
23. Thornton, M.J.; Kato, S.; Hibberts, N.A.; Brinklow, B.R.; Loudon, A.; Randall, V.A. Ability to culture dermal pa-pilla cells from red deer (cervus elaphus) hair follicles with differing hormonal responses in vivo offers a new model for studying the control of hair follicle biology. J. Exp. Zool. 1996, 275, 452. [CrossRef]

24. Inamatsu, M.; Matsuzaki, T.; Iwanari, H.; Yoshizato, K. Establishment of Rat Dermal Papilla Cell Lines that Sustain the Potency to Induce Hair Follicles from Afollicular Skin. J. Investig. Dermatol. 1998, 111, 767-775. [CrossRef] [PubMed]

25. Kishimoto, J.; Burgeson, R.E.; Morgan, B.A. Wnt signaling maintains the hair inducing activity of the dermal papilla. Genes Dev. 2000, 14, 1181-1185. [PubMed]

26. Ouji, Y.; Nakamura-Uchiyama, F.; Yoshikawa, M. Canonical Wnts, specifically Wnt- 10b, show ability to maintain dermal pa-pilla cells. Biochem. Biophys. Res. Commun. 2013, 438, 493-499. [CrossRef]

27. Qiao, J.; Zawadzka, A.; Philips, E.; Turetsky, A.; Batchelor, S.; Peacock, J.; Durrant, S.; Garlick, D.; Kemp, P.; Teumer, J. Hair follicle neogenesis induced by cultured human scalp dermal papilla cells. Regen. Med. 2009, 4, 667-676. [CrossRef]

28. Driskell, R.R.; Juneja, V.R.; Connelly, J.T.; Kretzschmar, K.; Tan, D.W.-M.; Watt, F.M. Clonal Growth of Dermal Papilla Cells in Hydrogels Reveals Intrinsic Differences between Sox2-Positive and -Negative Cells In Vitro and In Vivo. J. Investig. Dermatol. 2012, 132, 1084-1093. [CrossRef]

29. Ito, Y.; Hamazaki, T.S.; Ohnuma, K.; Tamaki, K.; Asashima, M.; Okochi, H. Isolation of Murine Hair-Inducing Cells Using the Cell Surface Marker Prominin-1/CD133. J. Investig. Dermatol. 2007, 127, 1052-1062. [CrossRef]

30. Arnold, K.; Sarkar, A.; Yram, M.A.; Polo, J.M.; Bronson, R.; Sengupta, S.; Seandel, M.; Geijsen, N.; Hochedlinger, K. Sox2 + Adult Stem and Progenitor Cells Are Important for Tissue Regeneration and Survival of Mice. Cell Stem Cell 2011, 9, 317-329. [CrossRef]

31. Rendl, M.; Lewis, L.; Fuchs, E. Molecular Dissection of Mesenchymal-Epithelial Interactions in the Hair Follicle. PLoS Biol. 2005, 3, e331. [CrossRef] [PubMed]

32. Driskell, R.R.; Giangreco, A.; Jensen, K.B.; Mulder, K.W.; Watt, F.M. Sox2-positive dermal papilla cells specify hair follicle type in mammalian epidermis. Development 2009, 136, 2815-2823. [CrossRef] [PubMed]

33. Handjiski, B.; Eichmüller, S.; Hofmann, U.; Czarnetzki, B.; Paus, R. Alkaline phosphatase activity and localization during the murine hair cycle. Br. J. Dermatol. 1994, 131, 303-310. [CrossRef]

34. Iida, M.; Ihara, S.; Matsuzaki, T. Hair cycle-dependent changes of alkaline phosphatase activity in the mesenchyme and epi-thelium in mouse vibrissal follicles. Dev. Growth Differ. 2010, 49, 185-195. [CrossRef]

35. Reynolds, A.J.; Jahoda, C.A. Hair matrix germinative epidermal cells confer follicle-inducing capabilities on dermal sheath and high passage papilla cells. Development 1996, 122, 3085-3094. [CrossRef] [PubMed]

36. Meuleman, N.; Tondreau, T.; Delforge, A.; Dejeneffe, M.; Massy, M.; Libertalis, M. Human marrow mesenchy-mal stem cell culture: Serum-free medium allows better expansion than classical $\alpha$-MEM medium. Eur. J. Hae-Matol. 2006, 76, 309-316. [CrossRef]

37. Messenger, A.; Jennifer, H.; Bleehen, S. The in vitro properties of dermal papilla cell lines established from human hair follicles. Br. J. Dermatol. 1986, 114, 425-430. [CrossRef]

38. Jahoda, C.; Oliver, R. The growth of vibrissa dermal papilla cells in vitro. Br. J. Dermatol. 1981, 105, 623-627. [CrossRef]

39. Almond-Roesler, B.; Schön, M.; Schön, M.P.; Blume-Peytavi, U.; Sommer, C.; Löster, K.; Orfanos, C.E. Cultured dermal papilla cells of the rat vibrissa follicle. Proliferative activity, adhesion properties and reorganization of the extracellular matrix in vitro. Arch. Dermatol. Res. 1997, 289, 698-704. [CrossRef]

40. Wessells, N.K.; Roessner, K.D. Nonproliferation in dermal condensations of mouse vibrissae and pelage hairs. Dev. Biol. 1965, 12, 419-433. [CrossRef]

41. Piérard, G.E.; De La Brassinne, M. Modulation of Dermal Cell Activity During Hair Growth in the Rat. J. Cutan. Pathol. 1975, 2, 35-41. [CrossRef] [PubMed]

42. Jahoda, C.A.; Reynolds, A.J.; Oliver, R.F. Induction of Hair Growth in Ear Wounds by Cultured Dermal Papilla Cells. J. Investig. Dermatol. 1993, 101, 584-590. [CrossRef] [PubMed]

43. Young, T.H.; Lee, C.Y.; Chiu, H.C.; Hsu, C.J.; Lin, S.J. Self-assembly of dermal papilla cells into inductive spheroidal mi-crotissues on poly(ethylene-co-vinyl alcohol) membranes for hair follicle regeneration. Biomaterials 2008, 29, 3521-3530. [CrossRef]

44. Hamano, T.; Teramoto, A.; Iizuka, E.; Abe, K. Effects of polyelectrolyte complex (PEC) on human periodontal ligament fi-broblast (HPLF) function. I. Three-dimensional structure of HPLF cultured on PEC. J. Biomed. Mater. Res. Part B Appl. Biomater. 1998, 41, 257-269. [CrossRef]

45. Koide, N.; Sakaguchi, K.; Koide, Y.; Asano, K.; Kawaguchi, M.; Matsushima, H.; Takenami, T.; Shinji, T.; Mori, M.; Tsuji, T. Formation of multicellular spheroids composed of adult rat hepatocytes in dishes with positively charged surfaces and under other nonadherent environments. Exp. Cell Res. 1990, 186, 227-235. [CrossRef]

46. Ryan, P.L.; Foty, R.A.; Kohn, J.; Steinberg, M.S. Tissue spreading on implantable substrates is a competitiveoutcome of cell-cell vs. cell-substratum adhesivity. Proc. Natl. Acad. Sci. USA 2001, 98, 4323-4327. [CrossRef] [PubMed]

47. Young, T.-H.; Tu, H.-R.; Chan, C.-C.; Huang, Y.-C.; Yen, M.-H.; Cheng, N.-C.; Chiu, H.-C.; Lin, S.-J. The enhancement of dermal papilla cell aggregation by extracellular matrix proteins through effects on cell-substratum adhesivity and cell motility. Biomaterials 2009, 30, 5031-5040. [CrossRef]

48. Neelamegham, S.; Munn, L.L.; Zygourakis, K. A model for the kinetics of homotypic cellular aggregation under static conditionsScienceDirect. Biophys. J. 1997, 72, 51-64. [CrossRef]

49. Lin, S.; Hsiao, W.; Young, T.; Yu, H.; Jee, S.S.J.L. Behavior of Human Melanocytes on Chitosan: From Monolayer to ThreeDimensional Spheroids. Ph.D. Thesis, National Taiwan University, Taipei, China, 2006. 
50. Biggs, L.C.; Mäkelä, O.J.; Myllymäki, S.-M.; Das Roy, R.; Närhi, K.; Pispa, J.; Mustonen, T.; Mikkola, M.L. Hair follicle dermal condensation forms via Fgf20 primed cell cycle exit, cell motility, and aggregation. eLife 2018, 7. [CrossRef]

51. Hashimoto, K.S. Ultrastructural study on Differentiation and Function of Hair. In Iology and Disease of the Hair Tokyo; Kobori, T., Montagna, W., Eds.; University of Tokyo Press: Tokyo, Japan, 1976; pp. 23-56.

52. Yamanishi, H.; Soma, T.; Yoshida, Y.; Ishimatsu, Y. Method for Promoting Hair Growth or Hair Regeneration by Maintaining or Increasing Expression of Cell-Adhesion Factor. U.S. Patent No 8,334,136, 18 December 2012.

53. Jacobson, C.M. A comparative study of the mechanisms by which X-irradiation and genetic mutation cause loss of vibrissae in embryo mice. J. Embryol. Exp. Morphol. 1966, 16, 369-379.

54. Newgreen, D.; Thiery, J.-P. Fibronectin in early avian embryos: Synthesis and distribution along the migration pathways of neural crest cells. Cell Tissue Res. 1980, 211, 269-291. [CrossRef] [PubMed]

55. Bronner-Fraser, M. An antibody to a receptor for fibronectin and laminin perturbs cranial neural crest development in vivo. Dev. Biol. 1986, 117, 528-536. [CrossRef]

56. Mauger, A.; Demarchez, M.; Herbage, D.; Grimaud, J.-A.; Druguet, M.; Hartmann, D.; Sengel, P. Immunofluorescent localization of collagen types I and III, and of fibronectin during feather morphogenesis in the chick embryo. Dev. Biol. 1982, 94, 93-105. [CrossRef]

57. Holbrook, K.A.; Smith, L.T.; Kaplan, E.D.; Minami, S.A.; Hebert, G.P.; Underwood, R.A. Expression of Morphogens During Human Follicle Development In Vivo and a Model for Studying Follicle Morphogenesis In Vitro. J. Investig. Dermatol. 1993, 101, S39-S49. [CrossRef]

58. Jiang, T.-X.; Chuong, C.-M. Mechanism of skin morphogenesis. I. Analyses with antibodies to adhesion molecules tenascin, N-CAM, and integrin. Dev. Biol. 1992, 150, 82-98. [CrossRef]

59. Couchman, J.R.; Gibson, W.T. Expression of basement membrane components through morphological changes in the hair growth cycle. Dev. Biol. 1985, 108, 290-298. [CrossRef]

60. Kaplan, E.D.; Holbrook, K.A. Dynamic expression patterns of tenascin, proteoglycans, and cell adhesion molecules during human hair follicle morphogenesis. Dev. Dyn. 1994, 199, 141-155. [CrossRef]

61. Schalkwijk, J.; Steijlen, P.M.; Van Vlijmen-Willems, I.M.; Oosterling, B.; Mackie, E.J.; Verstraeten, A.A. Tenascin expression in human dermis is related to epidermal proliferation. Am. J. Pathol. 1991, 139, 1143-1150.

62. Chuong, C.M.; Chen, H.M.; Jiang, T.X.; Chia, J. Adhesion Molecules in Skin Development: Morphogenesis of Feather and Hair. Ann. N. Y. Acad. Sci. 1991, 642, 263-280. [CrossRef] [PubMed]

63. Shames, R.B.; Jennings, A.G.; Sawyer, R.H. The initial expression and patterned appearance of tenascin in scutate scales is absent from the dermis of the scaleless (sc/sc) chicken. Dev. Biol. 1991, 147, 174-186. [CrossRef]

64. Lightner, V.A.; Gumkowski, F.; Bigner, D.D.; Erickson, H.P. Tenascin/hexabrachion in human skin: Biochemical identification and localization by light and electron microscopy. J. Cell Biol. 1989, 108, 2483-2493. [CrossRef] [PubMed]

65. Werb, Z. ECM and Cell Surface Proteolysis: Regulating Cellular Ecology. Cell 1997, 91, 439-442. [CrossRef]

66. Elliott, K.; Messenger, A.G.; Stephenson, T.J. Differences in Hair Follicle Dermal Papilla Volume are Due to Extracellular Matrix Volume and Cell Number: Implications for the Control of Hair Follicle Size and Androgen Responses. J. Investig. Dermatol. 1999, 113, 873-877. [CrossRef]

67. Botchkarev, V.A.; Kishimoto, J. Molecular Control of Epithelial-Mesenchymal Interactions During Hair Follicle Cycling. J. Investig. Dermatol. Symp. Proc. 2003, 8, 46-55. [CrossRef] [PubMed]

68. Ricard-Blum, S.; Ruggiero, F.; Van Der Rest, M. The Collagen Superfamily. Top. Curr. Chem. 2005, 247, 35-84. [CrossRef]

69. Jahoda, C.A.; Mauger, A.; Bard, S.; Sengel, P. Changes in fibronectin, laminin and type IV collagen distribution relate to basement membrane restructuring during the rat vibrissa follicle hair growth cycle. J. Anat. 1992, 181, 47-60.

70. Dublet, B.; Rest, M.V.D.; Ricardblum, S. Unconventional Collagens: Types VI, VII, VIII, IX, X, XII, XIV, XVI and XIX; Oxford University Press: Oxford, UK, 2000.

71. Gordon, M.K.; Hahn, R.A. Collagens. Cell Tissue Res. 2010, 339, 247. [CrossRef] [PubMed]

72. Sweeney, E.; Roberts, U.; Corbo, T.; Jacenko, O. Congenic Mice Confirm That Collagen X Is Required for Proper Hematopoietic Development. PLoS ONE 2010, 5, e9518. [CrossRef]

73. Plumb, D.A.D.; Mironov, A.; Ferrara, L.; Poulsom, R.; Kadler, K.E.; Thornton, D.J.; Briggs, M.D.; Boot-Handford, R.P. Collagen XXVII Is Developmentally Regulated and Forms Thin Fibrillar Structures Distinct from Those of Classical Vertebrate Fibrillar ColI-agens. J. Biol. Chem. 2007, 282, 12791-12795. [CrossRef]

74. Ricard-Blum, S. The collagen family. Cold Spring Harb. Perspect. Biol. 2011, 3, a004978. [CrossRef]

75. Myllyharju, J.; Kivirikko, K.I. Collagens, modifying enzymes and their mutations in humans, flies and worms. Trends Genet. 2004, 20,33-43.

76. Jabłońska-Trypuć, A.; Matejczyk, M.; Rosochacki, S. Matrix metalloproteinases (MMPs), the main extracellular matrix (ECM) enzymes in collagen degradation, as a target for anticancer drugs. J. Enzym. Inhib. Med. Chem. 2016, 31, 177-183. [CrossRef] [PubMed]

77. Bischoff, T.K. Physiology and pathophysiology of matrix metalloproteases. Amino Acids 2011, 41, $271-291$.

78. Han, S.; Makareeva, E.; Kuznetsova, N.V.; DeRidder, A.M.; Sutter, M.B.; Losert, W.; Phillips, C.L.; Visse, R.; Nagase, H.; Leikin, S. Molecular Mechanism of Type I Collagen Homotrimer Resistance to Mammalian Collagenases. J. Biol. Chem. 2010, 285, 22276-22281. [CrossRef] 
79. Abu-Abed, S.; Maclean, G.; Fraulob, V.; Chambon, P.; Dollé, P. Differential expression of the retinoic acid-metabolizing en-zymes CYP26A1 and CYP26B1 during murine organogenesis. Mech. Dev. 2020, 110, 173-177. [CrossRef]

80. Topletz, A.R.; Thatcher, J.E.; Zelter, A.; Lutz, J.D.; Tay, S.; Nelson, W.L.; Isoherranen, N. Comparison of the function and expression of CYP26A1 and CYP26B1, the two retinoic acid hydroxylases. Biochem. Pharmacol. 2012, 83, 149-163. [CrossRef]

81. Okano, J.; Levy, C.; Lichti, U.; Sun, H.-W.; Yuspa, S.H.; Sakai, Y.; Morasso, M.I. Cutaneous Retinoic Acid Levels Determine Hair Follicle Development and Downgrowth. J. Biol. Chem. 2012, 287, 39304-39315. [CrossRef] [PubMed]

82. Foitzik, K.; Spexard, T.; Nakamura, M.; Halsner, U.; Paus, R. Towards dissecting the pathogenesis of retinoid-induced hair loss: All-trans retinoic acid induces premature hair follicle regression (catagen) by upregulation of transforming growth fac-tor-beta2 in the dermal papilla. J. Investig. Dermatol. 2005, 124, 1119-1126. [CrossRef] [PubMed]

83. Everts, H.B. Endogenous retinoids in the hair follicle and sebaceous gland. Biochim. Biophys. Acta BBA Mol. Cell Biol. Lipids 2012, 1821, 222-229. [CrossRef]

84. Kwack, M.H.; Jang, Y.J.; Won, G.H.; Kim, M.K.; Kim, J.C.; Sung, Y.K. Overexpression of alkaline phosphatase improves the hair-inductive capacity of cultured human dermal papilla spheres. J. Dermatol. Sci. 2019, 95, 126-129. [CrossRef]

85. Higgins, C.A.; Richardson, G.D.; Ferdinando, D.; Westgate, G.E.; Jahoda, C.A. Modelling the hair follicle dermal papilla using spheroid cell cultures. Exp. Dermatol. 2010, 19, 546-548. [CrossRef] [PubMed]

86. Coffinier, C.; Tran, U.; Larraín, J.; De Robertis, E.; De Robertis, E. Neuralin-1 is a novel Chordin-related molecule expressed in the mouse neural plate. Mech. Dev. 2001, 100, 119-122. [CrossRef]

87. Nakayama, N.; Han, C.-Y.E.; Scully, S.; Nishinakamura, R.; He, C.; Zeni, L.; Yamane, H.; Chang, D.; Yu, D.; Yokota, T.; et al. A Novel Chordin-like Protein Inhibitor for Bone Morphogenetic Proteins Expressed Preferentially in Mesenchymal Cell Lineages. Dev. Biol. 2001, 232, 372-387. [CrossRef]

88. Balemans, W.; Hul, W.V. Extracellular Regulation of BMP Signaling in Vertebrates: A Cocktail of Modulators. Dev. Biol. 2002, 250, 231-250. [CrossRef] [PubMed]

89. Bolger, A.M.; Lohse, M.; Usadel, B. Trimmomatic: A flexible trimmer for Illumina sequence data. Bioinformatics 2014, 30, 2114-2120. [CrossRef]

90. Kim, D.; Langmead, B.; Salzberg, S.L. HISAT: A fast spliced aligner with low memory requirements. Nat. Methods 2015, 12,357-360. [CrossRef] [PubMed]

91. Roberts, A.; Pachter, L. Streaming fragment assignment for real-time analysis of sequencing experiments. Nat. Methods 2013, 10, 71-73. [CrossRef]

92. Langmead, B.; Salzberg, S.L. Fast gapped-read alignment with Bowtie 2. Nat. Methods 2012, 9, 357-359. [CrossRef]

93. Warnes, G.R.; Bolker, B.; Bonebakker, L.; Gentleman, R.; Huber, W.; Liaw, A.; Lumley, T.; Maechler, M.; Magnusson, A.; Moeller, S.; et al. gplots: Various R Programming Tools for Plotting Data. 2020. Available online: https://CRAN.R-project.org/package= gplots (accessed on 15 March 2020).

94. Frank, E.; Harrell, E., Jr. Hmisc: Harrell Miscellaneous. Available online: https://CRAN.R-project.org/package=Hmisc (accessed on 20 March 2020).

95. Taiyun, W.V.S. Corrplot: Visualization of a Correlation Matrix. 2017. Available online: https://CRAN.R-project.org/package= corrplot (accessed on 15 March 2020).

96. Wickham, H. ggplot2: Elegant Graphics for Data Analysis; Springer: New York, NY, USA, 2016; ISBN 978-3-319-24277-4.

97. Love, M.I.H.W.; Anders, S. Moderated estimation of fold change and dispersion for RNA-seq data with DESeq2. Genome Biol. 2014, 15, 550. [CrossRef] [PubMed]

98. Sherman, B.T.; Lempicki, R.A. Systematic and integrative analysis of large gene lists using DAVID Bioinformatics Resources. Nature Protoc. 2009, 4, 44-57. 